\title{
Empleo de osteosíntesis recubierta de cemento con antibiótico en el tratamiento de la osteomielitis. Presentación de dos casos
}

\author{
Jorge L. Soutullo, Santiago Argüelles, Martín P. Rodríguez, Enrique Pereira \\ Equipo de Mano y Miembro Superior, Instituto Argentino de Diagnóstico y Tratamiento, \\ Ciudad Autónoma de Buenos Aires, Argentina
}

\section{RESUMEN}

El tratamiento de la osteomielitis asociada a la falla de la osteosíntesis representa un verdadero desafío para el cirujano ortopédico. El retiro del implante, la limpieza quirúrgica del área afectada y la fijación externa como métodos de estabilidad transitoria, sumados a la administración de antibióticos por vía sistémica son conductas habituales en el manejo inicial de la infección asociada a la falla del implante. No obstante, la suma de estas medidas puede no ser suficiente para controlar completamente el cuadro. El agregado local de cemento con antibiótico permite la liberación continua y sostenida del agente que alcanza una concentración local significativamente más alta que las concentraciones inhibitorias bacterianas mínimas necesarias, a expensas de una menor toxicidad sistémica. Se presentan dos casos de osteomielitis asociada a la falla de la osteosíntesis tratados mediante una nueva síntesis con placa revestida de cemento con antibiótico. Se logró controlar la infección y la consolidación ósea en ambos casos. El resultado funcional fue excelente con un puntaje QuickDASH de 6,3 y 4,5, respectivamente.

Palabras clave: Osteomielitis; placa recubierta; cemento con antibiótico; falla de osteosíntesis.

Nivel de Evidencia: IV

Osteomyelitis treatment with antibiotic cement-coated plate fixation. Two case reports

\section{ABSTRACT}

Treatment of osteomyelitis associated with osteosynthesis failure represents a real challenge for the orthopedic surgeon. Implant removal, surgical debridement of the affected area, and external fixation as a temporary stabilization method coupled with antibiotic therapy administered by the systemic route constitute the basis for the initial management of infections associated with implant failure. However, this combined management may prove inadequate to achieve complete control of the infection. The local use of antibiotic-loaded cement allows for maintaining a sustained agent release that reaches significantly higher concentrations than the minimum required bacterial inhibitory concentrations while reducing the associated systemic toxicity. We present two cases of osteomyelitis associated with osteosynthesis failure treated with a second osteosynthesis procedure with an antibiotic cementcoated plate. Infection control and bone union were achieved in both cases. The functional outcome was excellent with QuickDASH scores of 6.3 and 4.5 points, respectively.

Key words: Osteomyelitis; antibiotic cement-coated plate; osteosynthesis failure.

Level of Evidence: IV

\section{INTRODUCCIÓN}

El tratamiento de la osteomielitis asociada a una falla de la osteosíntesis representa un verdadero desafío para el cirujano ortopédico. El retiro del implante, la limpieza quirúrgica del área afectada y la fijación externa como métodos de estabilidad transitoria, sumados a la administración de antibióticos por vía sistémica son conductas habituales en el manejo inicial de la infección asociada a la falla del implante. No obstante, la suma de estas medidas puede

Recibido el 24-6-2019. Aceptado luego de la evaluación el 18-11-2019 • Dr. JORGE L. SOUTULLO • jorge_soutullo@ hotmail.com ID https://orcid.org/0000-0001-9540-4849 Cómo citar este artículo: Soutullo JL, Argüelles S, Rodríguez MP, Pereira E. Empleo de osteosíntesis recubierta de cemento con antibiótico en el tratamiento de la osteomielitis. Presentación de dos casos. Rev Asoc Argent Ortop Traumatol 2020;85(4):403-417. https://doi.org/10.15417/issn. 1852-7434.2020.85.4.1004 
ser insuficiente para controlar completamente el cuadro. El agregado local de cemento con antibiótico permite la liberación continua y sostenida del agente que alcanza una concentración local significativamente más alta que las concentraciones inhibitorias bacterianas mínimas necesarias, a expensas de una menor toxicidad sistémica. ${ }^{1,2}$

El objetivo de este artículo es presentar dos casos de osteomielitis asociados a la falla de la osteosíntesis, tratados mediante una nueva síntesis con placa revestida de cemento con antibiótico.

\section{CASO CLÍNICO 1}

Hombre de 61 años, sin antecedentes clínicos de relevancia, que consulta a las seis semanas de una reducción abierta y fijación interna con placa y tornillos en el cúbito derecho para tratar una luxo-fractura de Monteggia. Tiene una colostomía como tratamiento temporario de una lesión abdominal. El examen físico revela una tumefacción en el codo y el antebrazo derechos, una fístula en la región de la cicatriz quirúrgica con abundante secreción de aspecto purulento, severa limitación de la movilidad pasiva del codo y parálisis del nervio interóseo posterior. Las radiografías muestran una luxación anterior de la cúpula radial, deseje del cúbito sin consolidación y rotura del material de osteosíntesis (Figura 1). Los análisis bioquímicos indicaron un aumento de la eritrosedimentación y la proteína $\mathrm{C}$ reactiva.
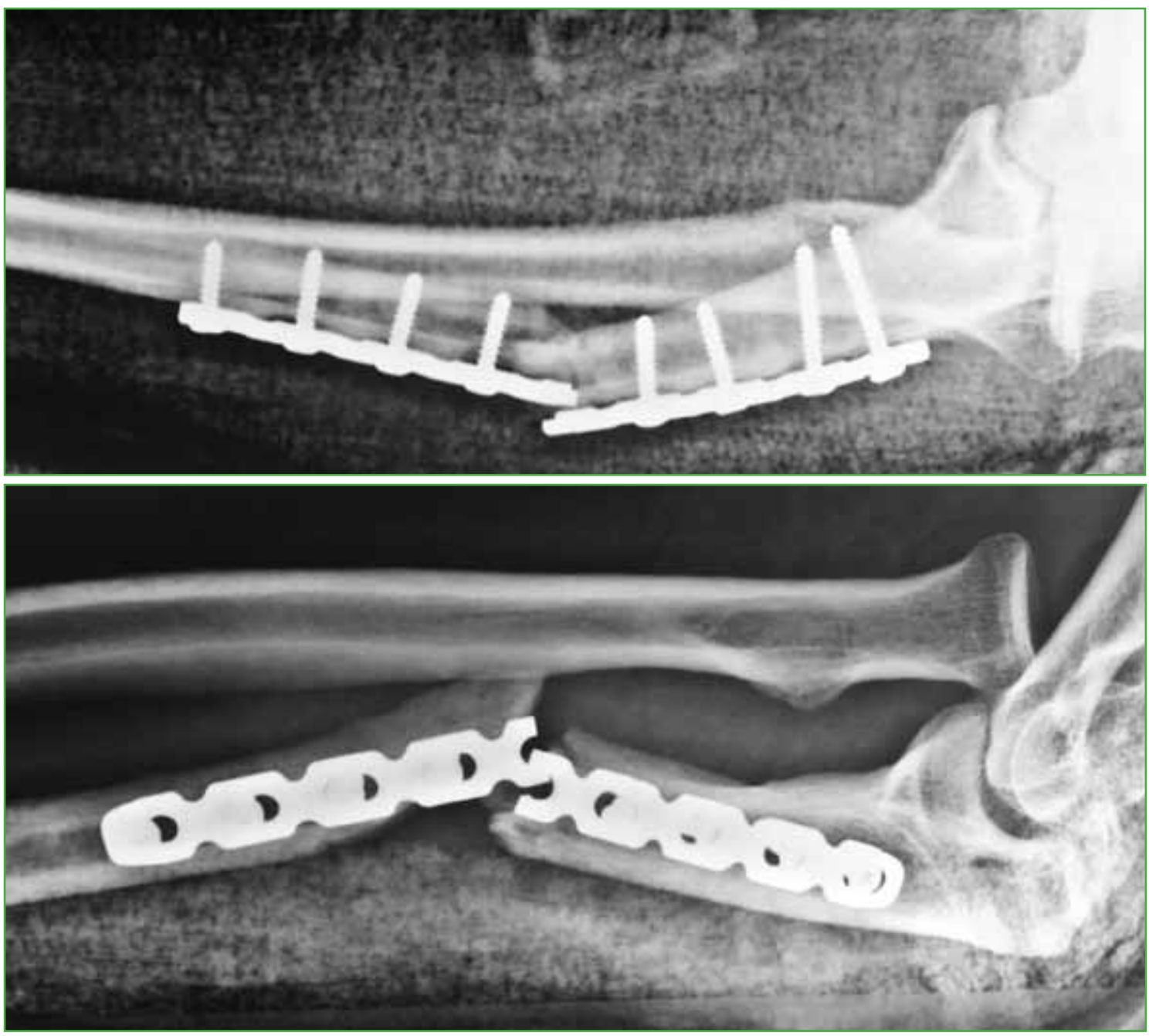

Figura 1. Radiografías de antebrazo derecho. Se observan la rotura del material de osteosíntesis, el deseje y la luxación anterior de la cúpula radial. 
Inicialmente se realizó una limpieza quirúrgica, se retiró el material de osteosíntesis, y se procedió a la reducción directa y la fijación externa con tutor tubular tipo AO (Figura 2). La articulación radiocapitelar fue reducida en forma cerrada y se tomaron múltiples muestras para cultivo y estudio anatomopatológico. El paciente recibió tratamiento antibiótico empírico hasta contar con el resultado del análisis bacteriológico. Se aislaron los siguientes gérmenes: Enterococcus faecalis, Enterobacter cloacae, Aeromonas hydrophila y Pseudomonas aeruginosa.

A

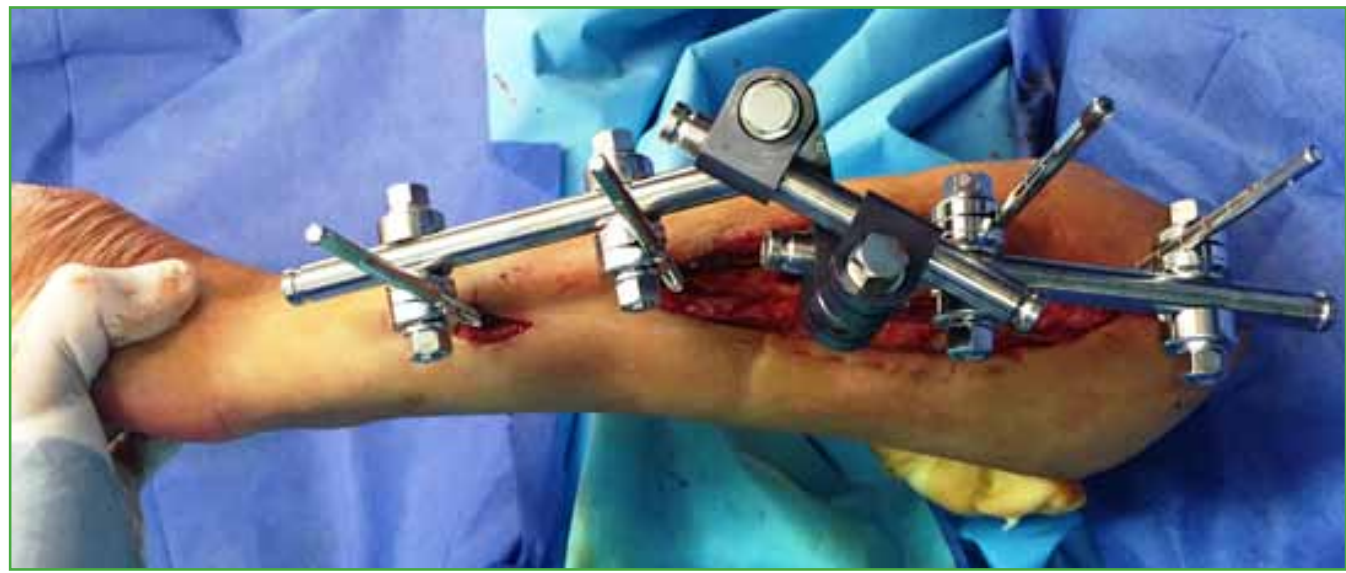

B
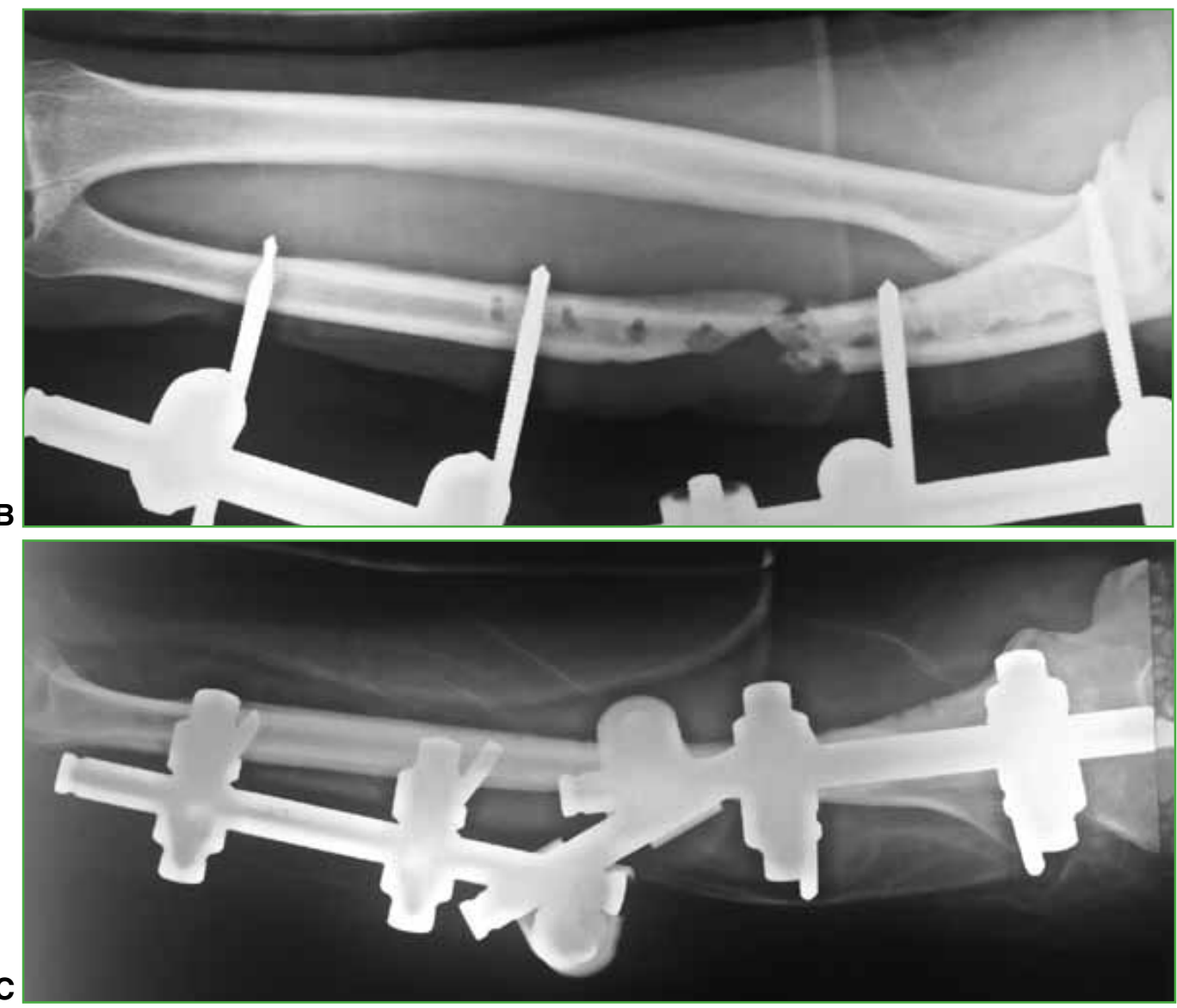

Figura 2. A. Imagen intraoperatoria. B y C. Radiografías de antebrazo derecho luego de la limpieza quirúrgica y la fijación externa. 
Tras cinco semanas de tratamiento antibiótico específico, los valores de eritrosedimentación y proteína C reactiva estaban disminuyendo y la evolución clínica era favorable, por lo que se realizó una nueva limpieza quirúrgica, se retiró la fijación externa y se practicó una nueva síntesis con placa de 3,5 $\mathrm{mm}$ revestida de cemento con vancomicina y tobramicina (según antibiograma). Se utilizó injerto tricortical de cresta ilíaca para rellenar el defecto óseo de 2,5 cm del cúbito (Figuras 3 y 4 ).

A
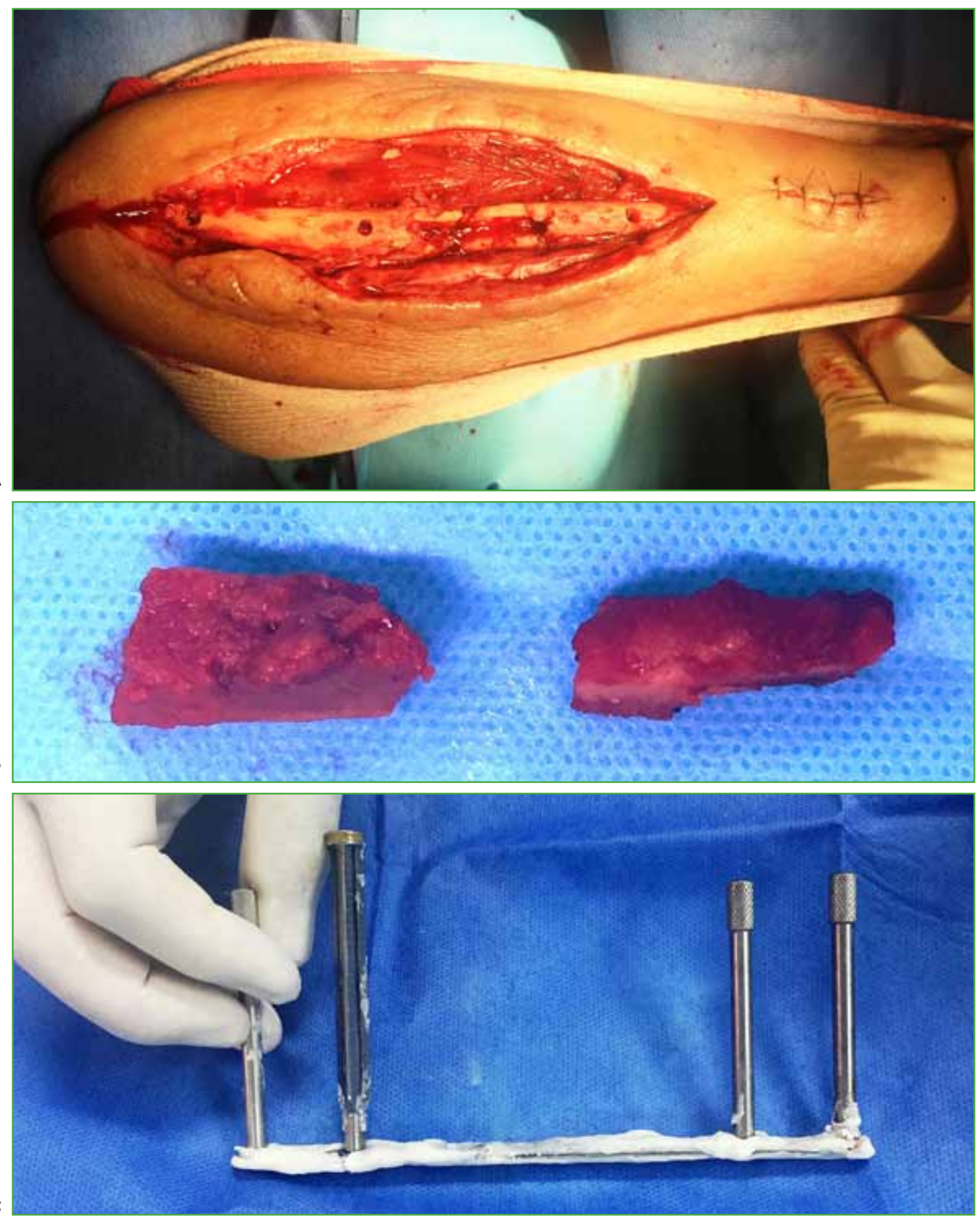

Figura 3. A. Imagen intraoperatoria luego de retirar el tutor externo. B. Injerto óseo tricortical de cresta ilíaca. C. Cementación de la placa con preservación de la rosca de los orificios a través de las guías de bloqueo. 
A
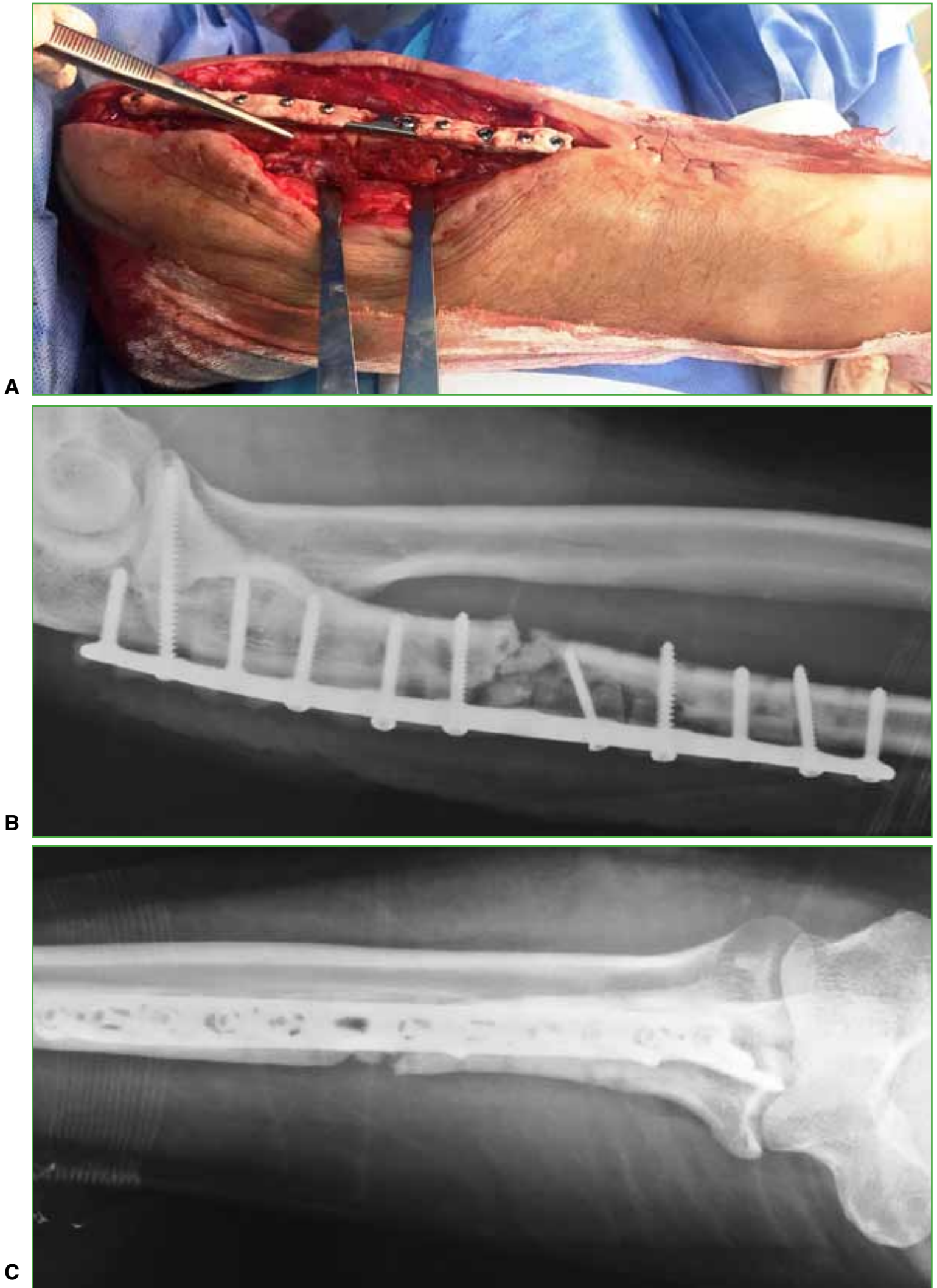

Figura 4. A. Imagen intraoperatoria que revela la osteosíntesis cubierta de cemento con antibióticos más la colocación de injerto óseo. B y C. Control radiográfico. 
El paciente no tuvo complicaciones en el período posoperatorio, y utilizó una inmovilización braquipalmar durante tres semanas, luego, comenzó con la rehabilitación. Posteriormente la muñeca fue inmovilizada con una férula antebraquipalmar como parte del tratamiento de la parálisis del nervio interóseo posterior.

A las 24 semanas, se observó la consolidación radiográfica (Figura 5). La recuperación neurológica fue completa. Tras un año de seguimiento, el paciente no tenía síntomas ni signos de infección. Los valores de eritrosedimentación y proteína C reactiva eran normales. El puntaje del cuestionario QuickDASH era de 6,3. El implante fue retirado a los 18 meses y los resultados de los cultivos fueron negativos (Figura 6).

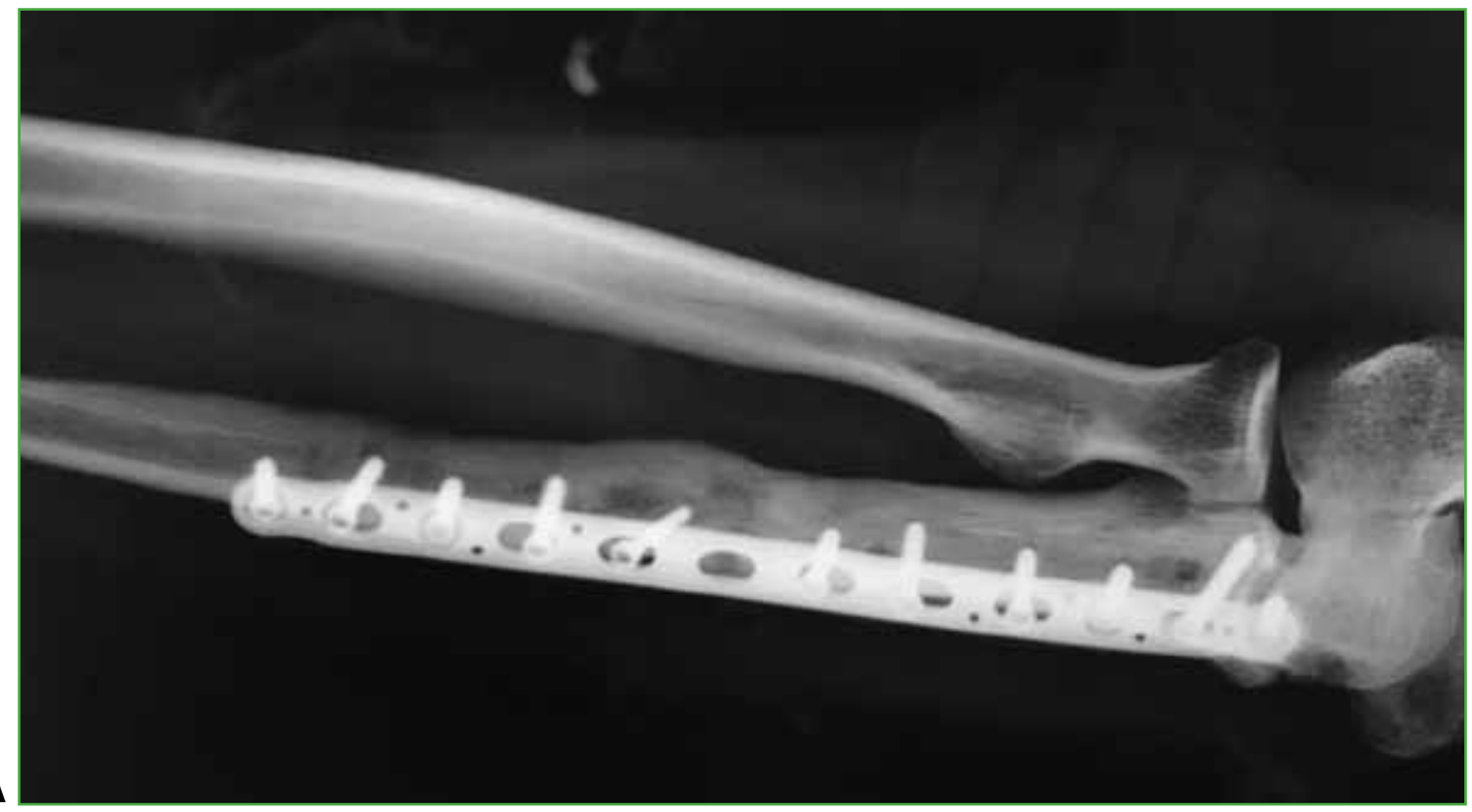

A

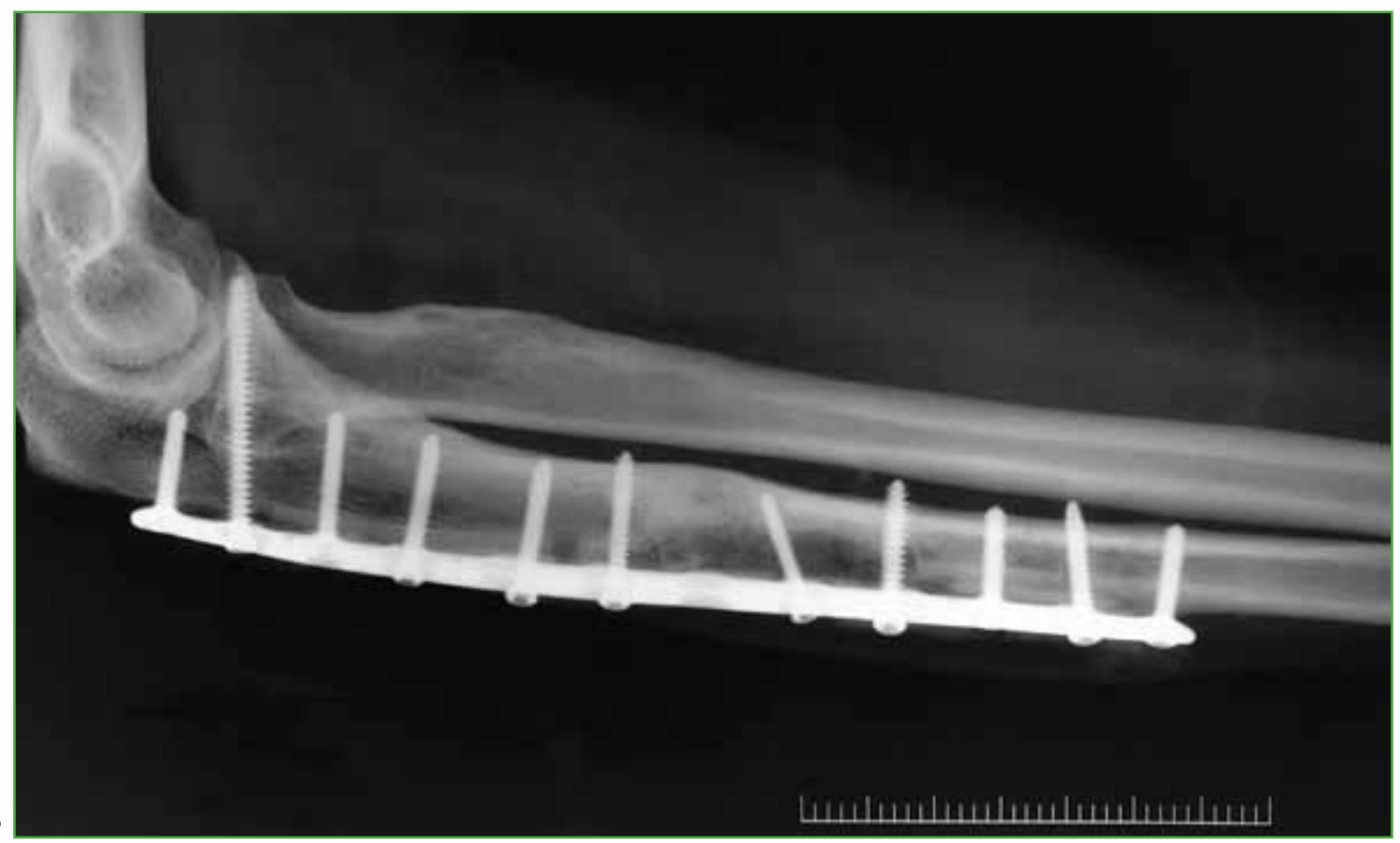

Figura 5. A y B. Radiografías a las 24 semanas. Se observa la integración del injerto y la consolidación de la fractura. 

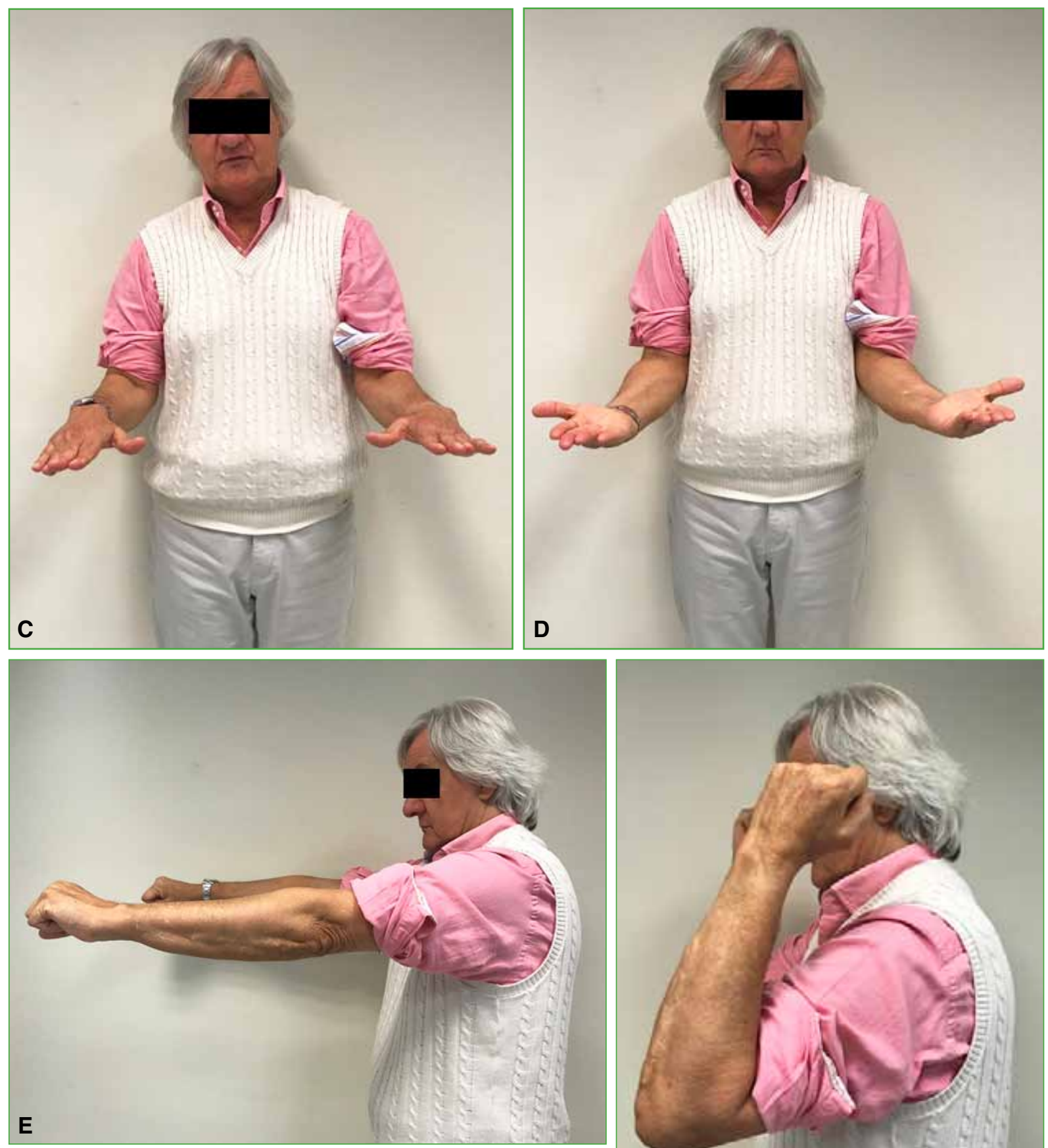

Figura 5. C-F. Examen físico a las 24 semanas.

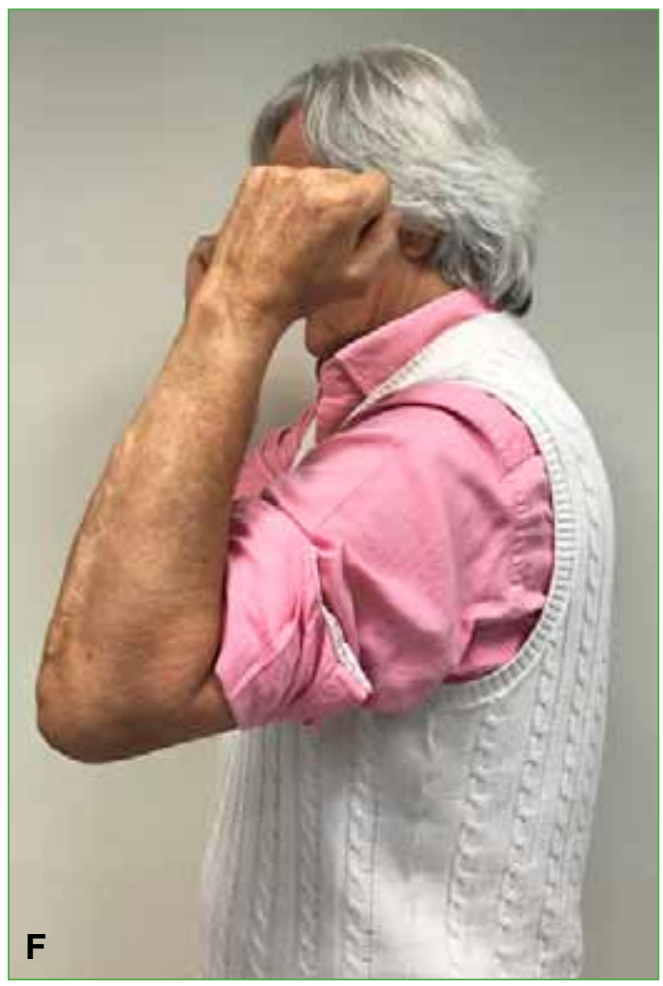



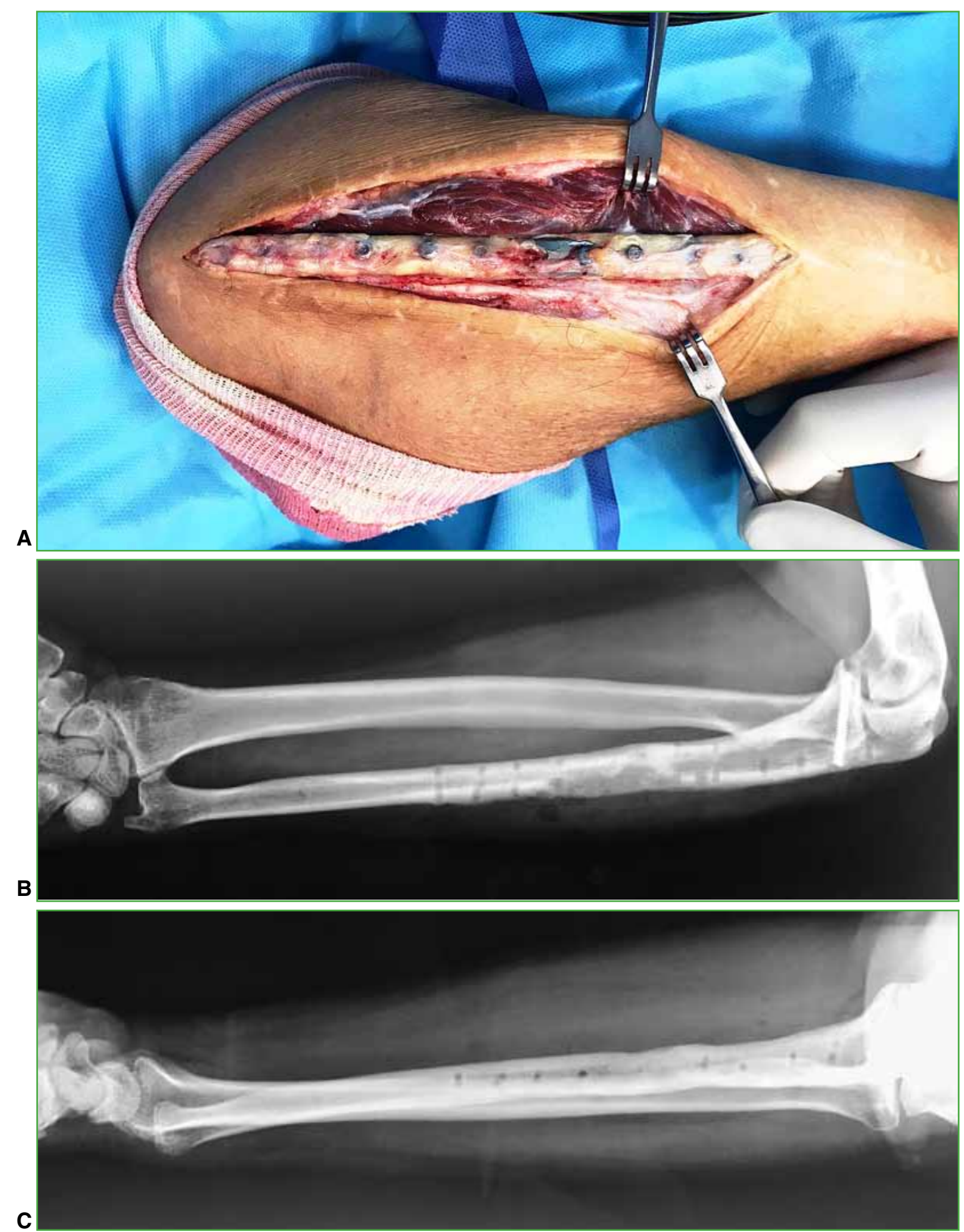

Figura 6. Retiro definitivo del implante a los 18 meses. A. Imagen intraoperatoria. B y C. Control radiográfico. 


\section{CASO CLÍNICO 2}

Hombre de 56 años, sin antecedentes clínicos de relevancia. Consultó por dolor e impotencia funcional en el codo derecho a las cinco semanas de una reducción abierta y fijación interna con doble placa y tornillos por fractura de húmero distal. En el examen físico, se constata eritema y tumefacción en el codo derecho y limitación importante de la movilidad activa (Figura 7). Las radiografías revelan una pérdida de la reducción con falla de la osteosíntesis (Figura 8). En el análisis bioquímico, se detectó leucocitosis con aumento de la eritrosedimentación y la proteína $\mathrm{C}$ reactiva.

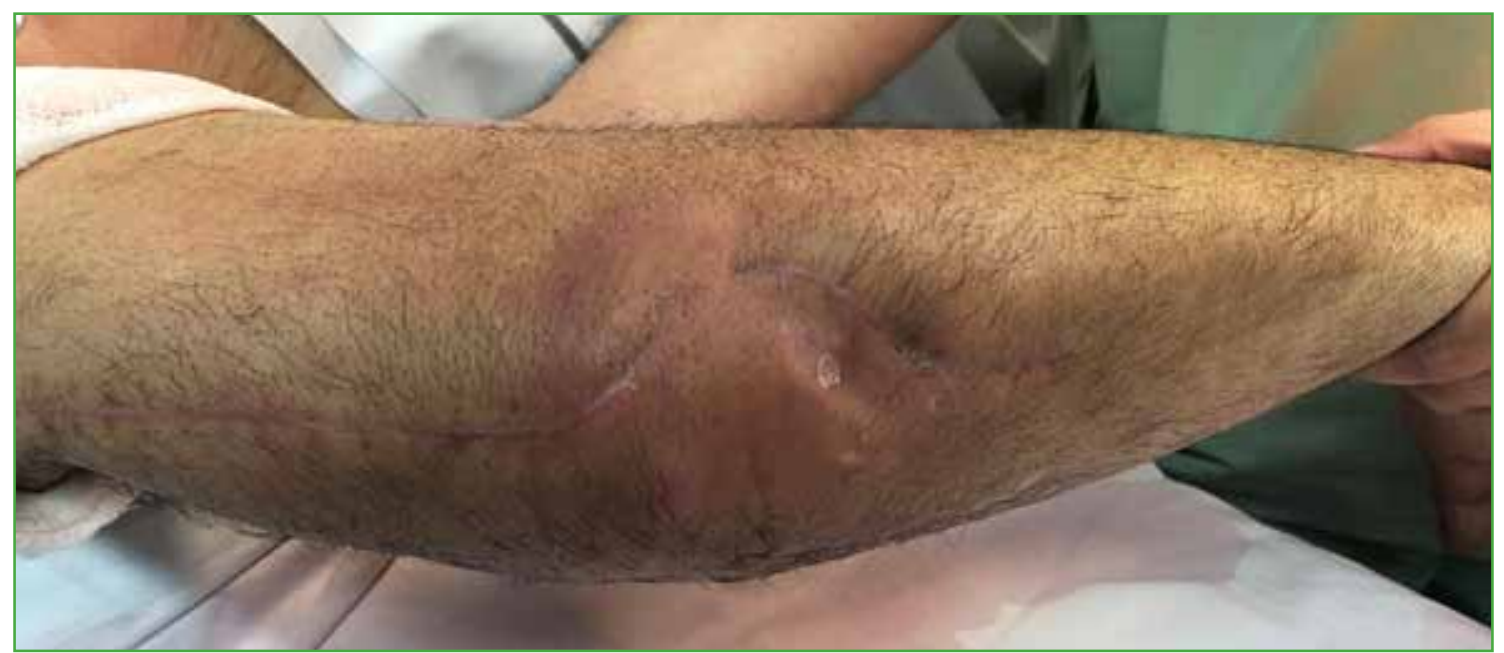

Figura 7. Tumefacción y eritema en la región de la cicatriz previa
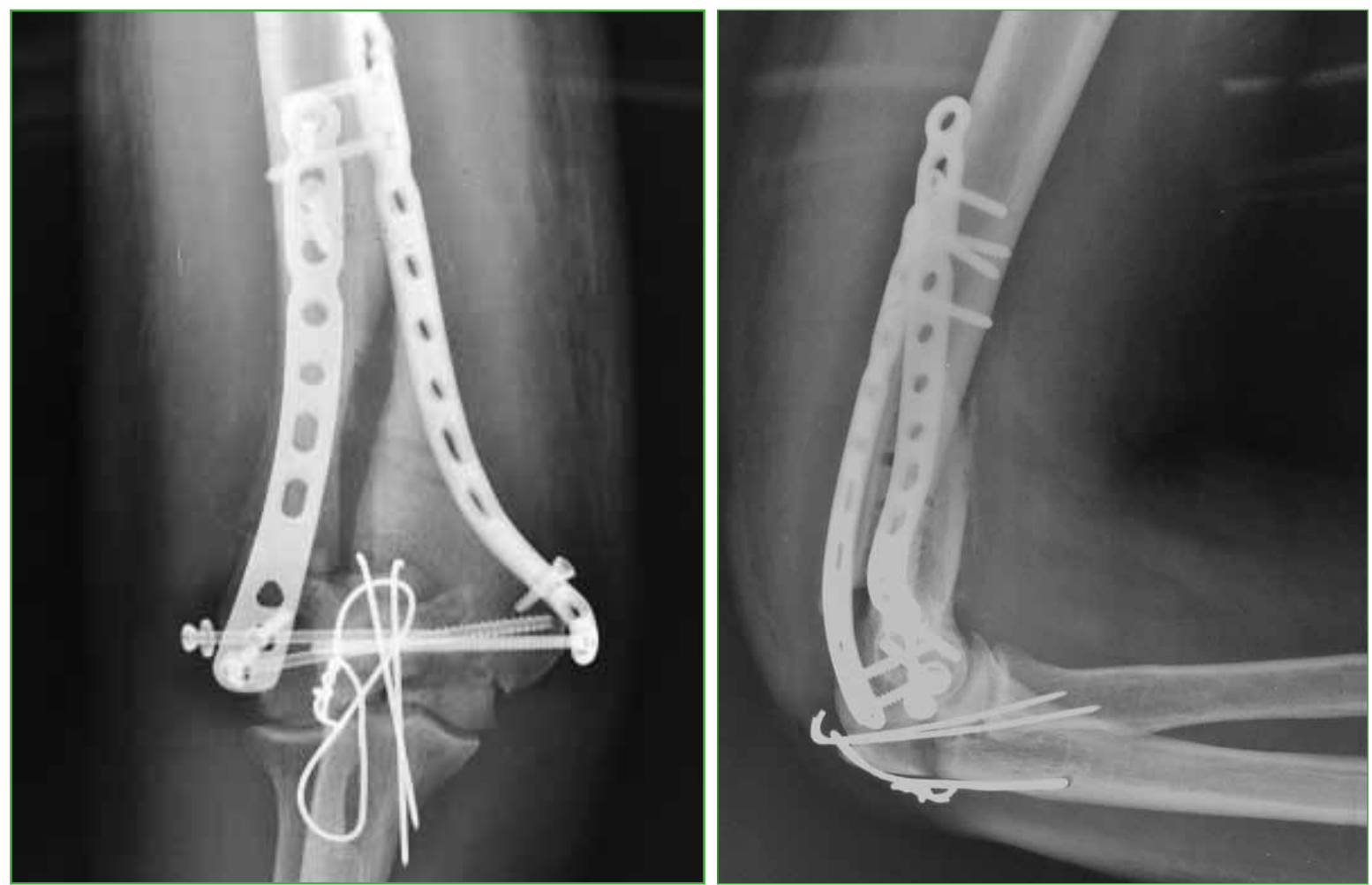

Figura 8. Radiografías de codo derecho. Se observa la falla de la osteosíntesis. 
Se realizó una limpieza quirúrgica, se tomaron múltiples muestras para cultivo y anatomía patológica. En el período posoperatorio, el paciente recibió tratamiento antibiótico empírico hasta que se aisló $S$. epidermidis en todas las muestras.

La evolución clínica fue favorable. Tras nueve días de tratamiento antibiótico específico y con valores de eritrosedimentación y proteína $\mathrm{C}$ reactiva en descenso, se realizó la cirugía de revisión en un tiempo que consistió en una limpieza quirúrgica, el retiro de la osteosíntesis colocada (Figura 9), la nueva reducción y fijación con placas anatómicas revestidas de cemento con antibiótico, según el antibiograma (vancomicina y tobramicina) (Figura 10).

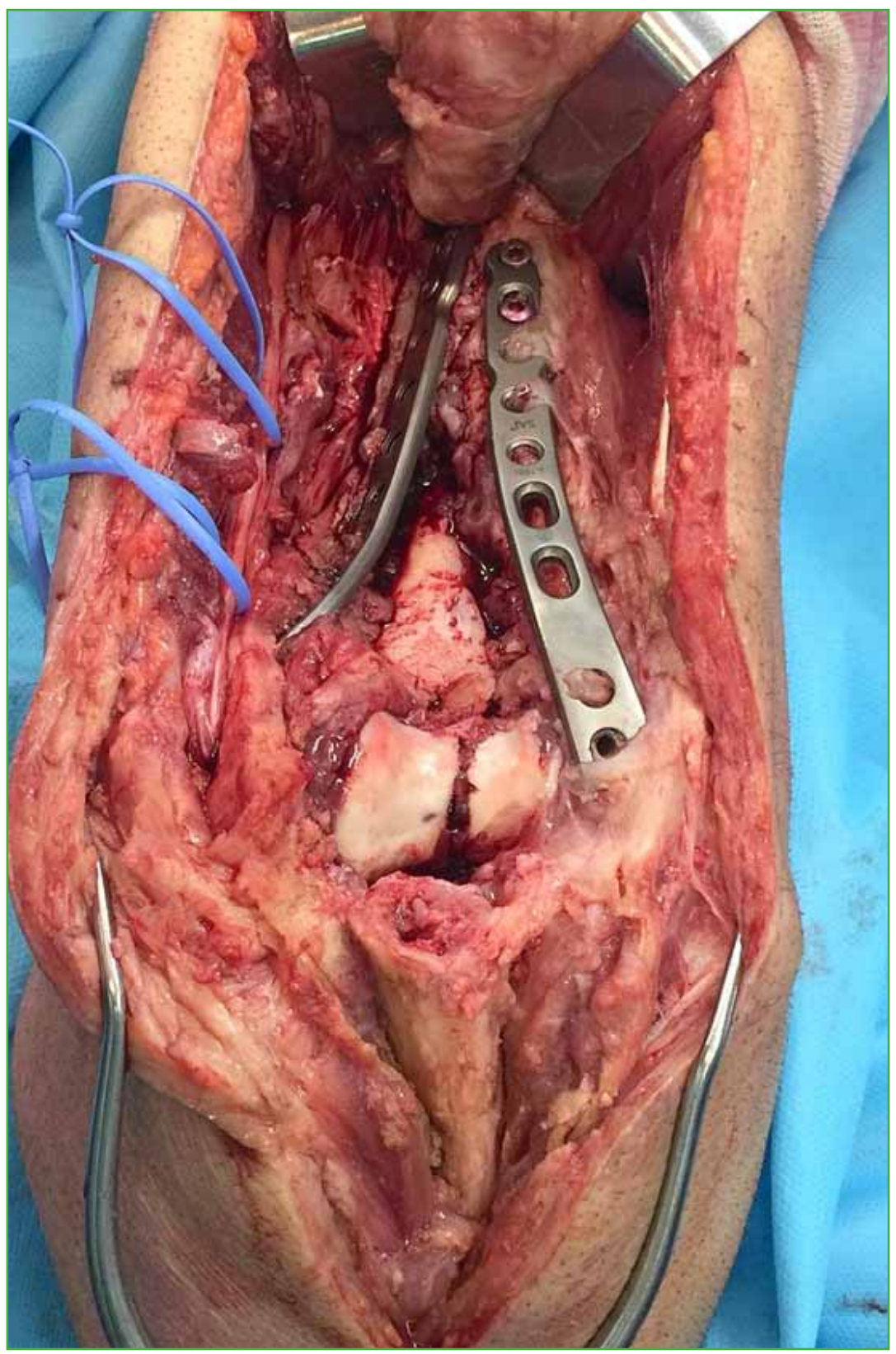

Figura 9. Imagen intraoperatoria. Se observa la pérdida de la reducción del foco fracturario. 

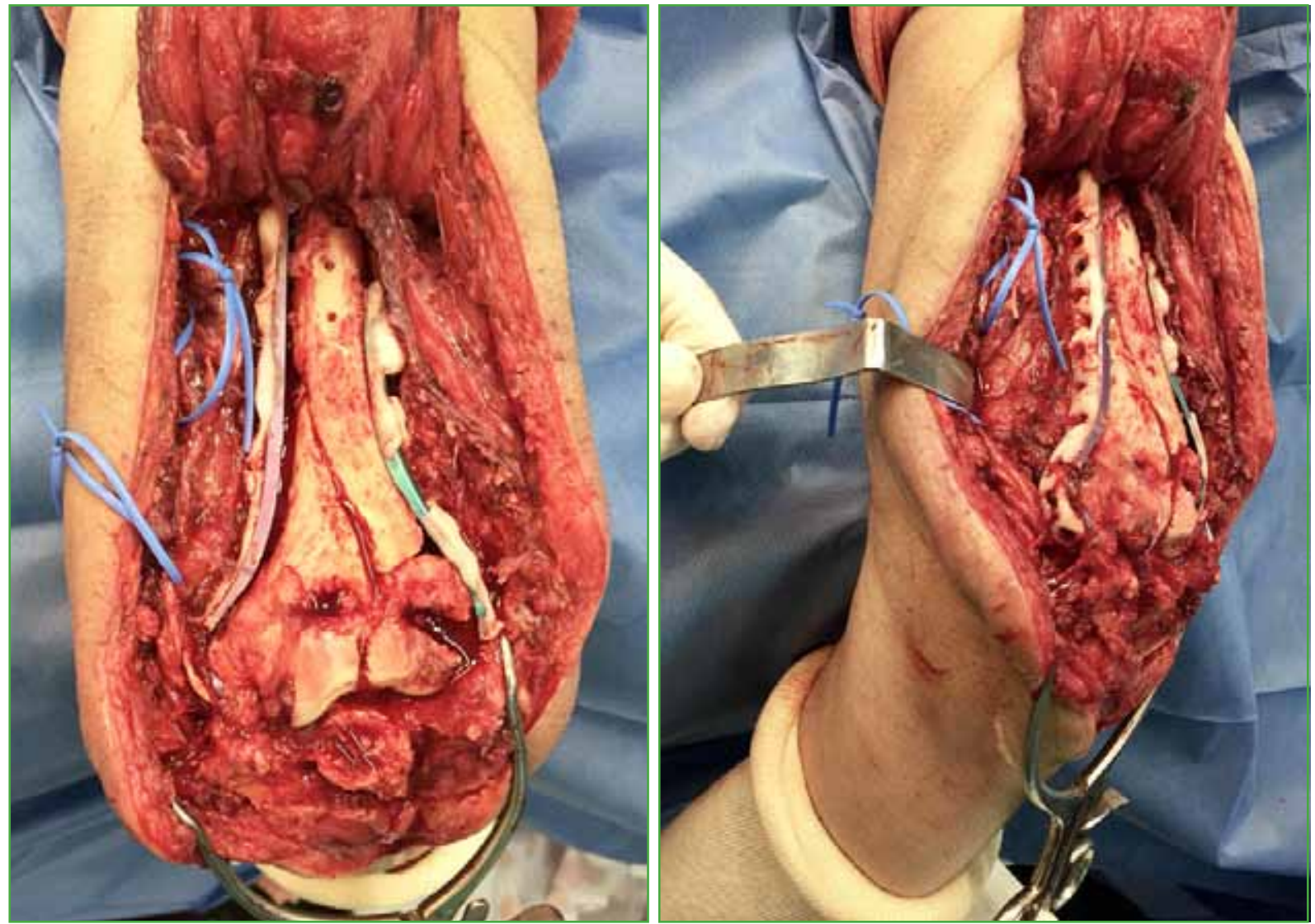

Figura 10. Imágenes intraoperatorias. Colocación de doble placa en una configuración a $180^{\circ}$ revestidas de cemento con antibiótico.

El paciente evolucionó sin complicaciones después de la cirugía. El codo fue inmovilizado con una valva braquipalmar durante dos semanas y, luego, con una férula articulada, a continuación, comenzó con el programa de rehabilitación (Figura 11). A las 12 semanas, se observó la consolidación radiográfica (Figura 12). A los seis meses, los valores de eritrosedimentación y proteína $\mathrm{C}$ reactiva eran normales. El puntaje del cuestionario QuickDASH era de 4,5 (Figura 13).

\section{DISCUSIÓN}

La osteomielitis asociada a una falla de la osteosíntesis representa un verdadero desafío tanto para el paciente como para el cirujano, debido a la alta morbilidad.

El retiro del implante, la limpieza quirúrgica del área afectada y la fijación externa como métodos de estabilidad transitoria, sumados a la administración de antibióticos por vía sistémica son conductas habituales en el manejo inicial de la infección asociada a la falla del implante..$^{1,2}$ No obstante, la suma de estas medidas puede ser insuficiente para controlar completamente el cuadro. Por este motivo, el agregado local de cemento con antibiótico permite la liberación continua y sostenida del agente durante un tiempo determinado. Esto resultaría beneficioso al permitir alcanzar una concentración local significativamente más alta que las concentraciones inhibitorias bacterianas mínimas necesarias, a expensas de una menor toxicidad sistémica. ${ }^{1,2}$

La placa revestida de cemento con antibiótico es una variante en la colocación y liberación de antibióticos locales (p. ej., perlas, rosarios, espaciadores, etc.), pero, a diferencia de otras, posibilita la estabilización de la fractura, evita la adherencia bacteriana al material de osteosíntesis e induce, a través del cemento, la generación de una seudomembrana que favorece la consolidación ósea. ${ }^{3}$ Pelissier y cols. demostraron que esta seudomembrana puede producir factores de crecimiento y de osteoinducción capaces de diferenciarse en células de la línea osteoblástica, que podría favorecer la osteointegración del injerto y, con ello, la consolidación de la fractura. ${ }^{3}$ 


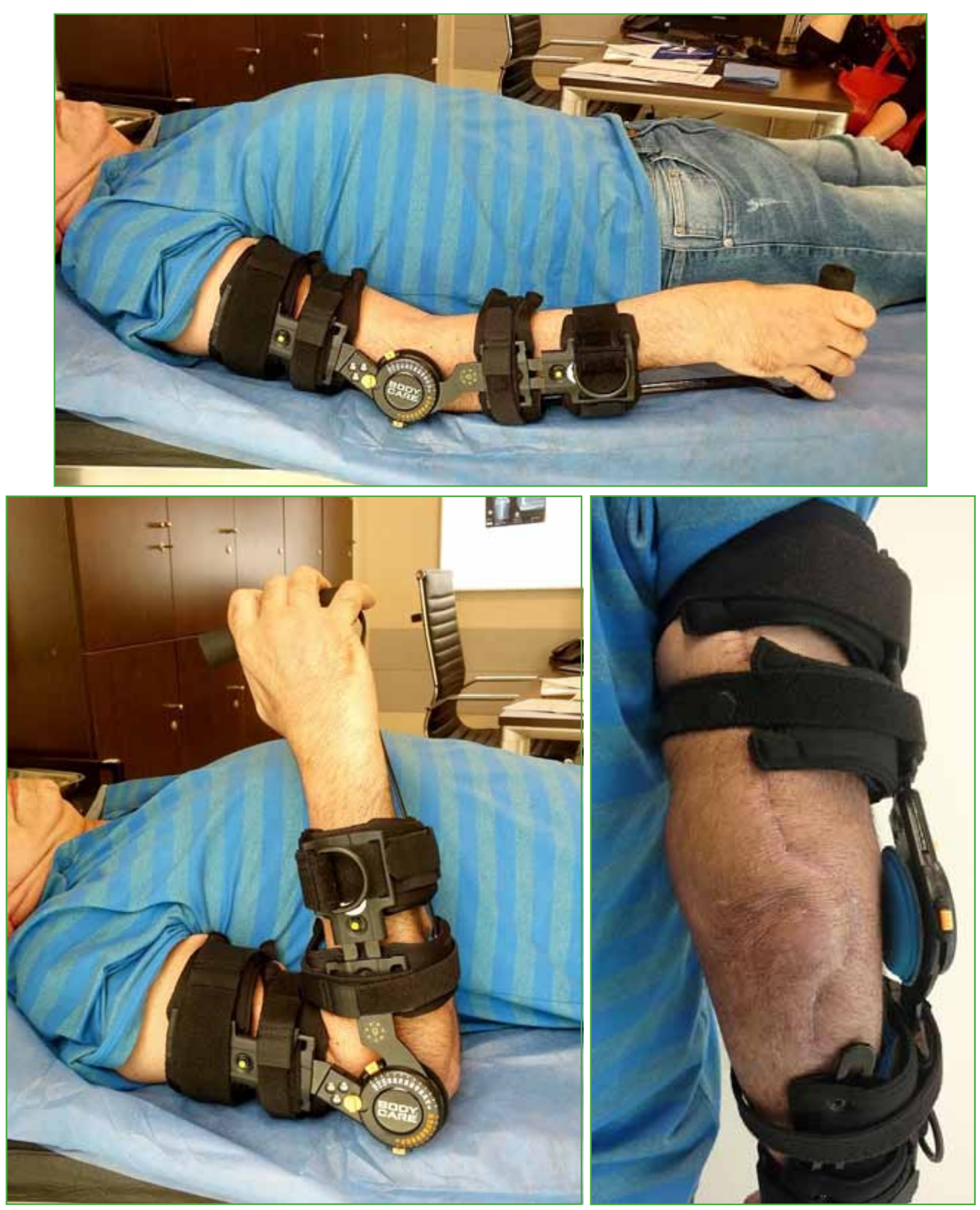

Figura 11. Movilidad activa asistida con férula articulada de codo, a las 7 semanas de la cirugía. 

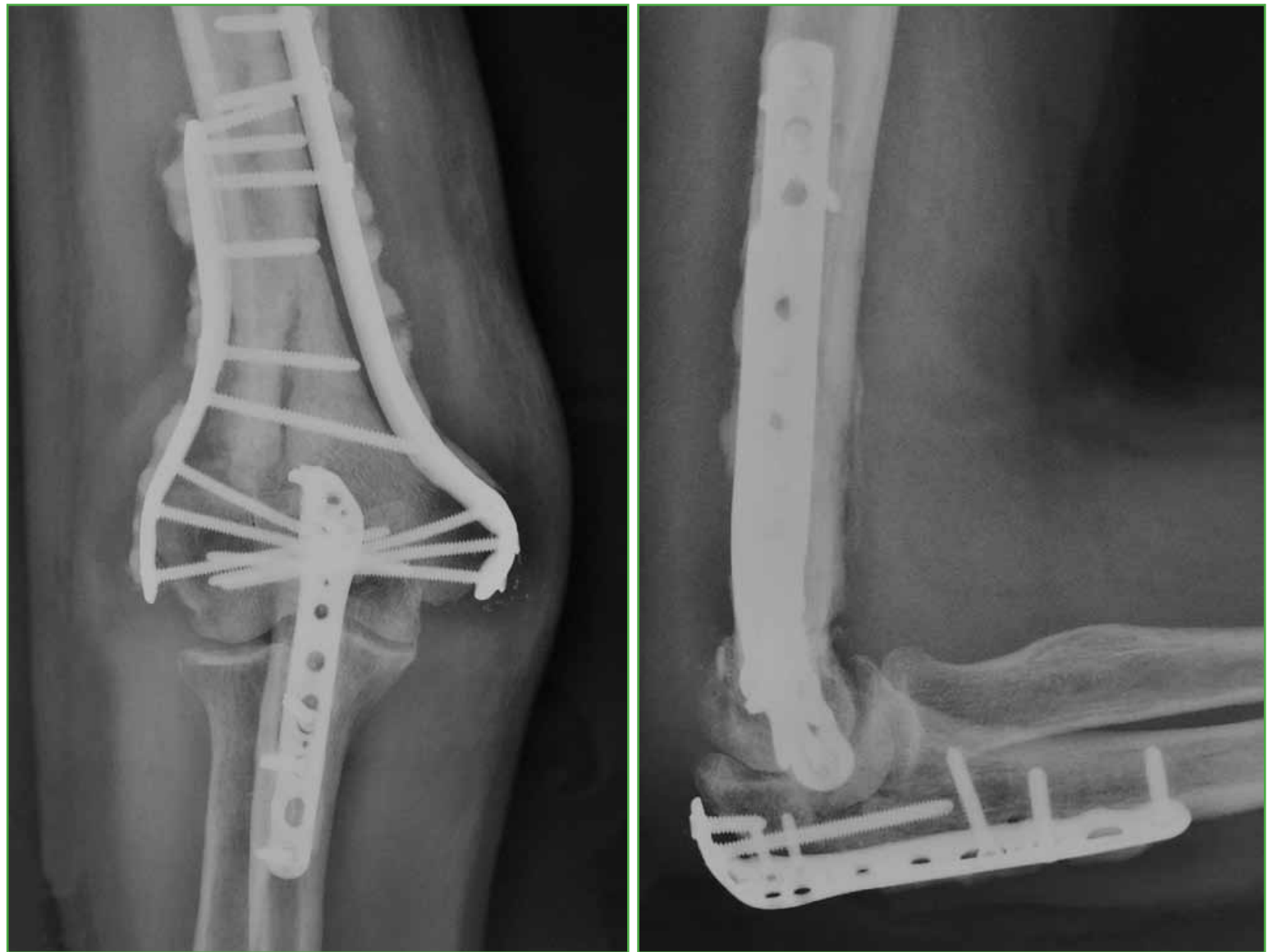

Figura 12. Radiografías a las 9 semanas de la cirugía. Consolidación ósea.
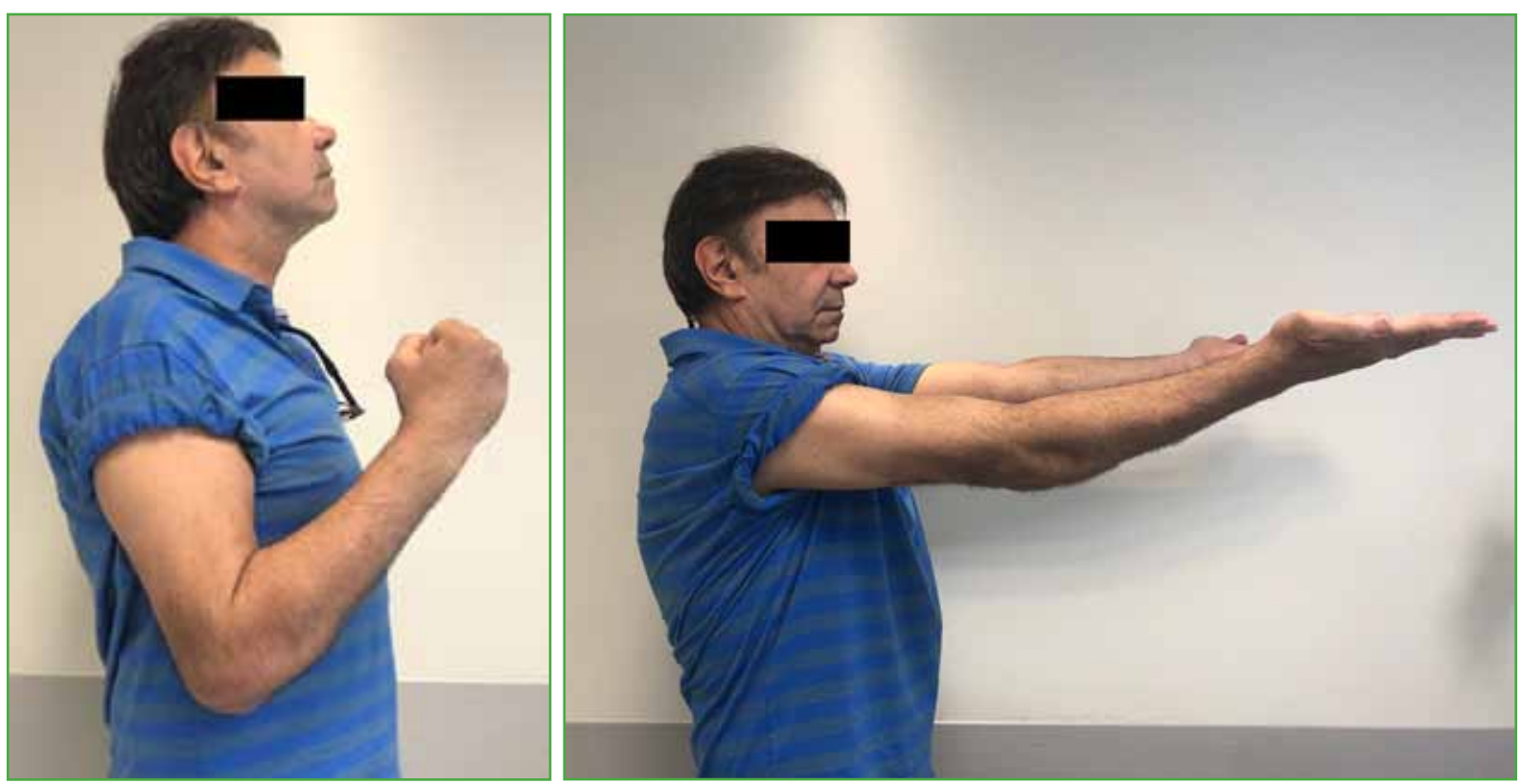

Figura 13. Rango de movilidad a los 6 meses de la cirugía. 
Se han estudiado múltiples elementos como vehículo para lograr la liberación local de los antibióticos. La policapralactona, las esponjas de colágeno, la hidroxiapatita de calcio y los implantes de fibrina no han tenido diferencias significativas en cuanto al gradiente de elución al ser comparados con el polimetacrilato. ${ }^{4-6}$

La elección del antibiótico para utilizar con el cemento de polimetacrilato dependerá de los siguientes factores: 1) el espectro de acción, 2) la estabilidad térmica y 3) las características de elución.?

Se ha observado un efecto sinérgico utilizando combinaciones de antibióticos, como vancomicina y tobramicina. Adams y cols. estudiaron esta interacción y registraron aumentos de la concentración local del 103\% y 68\%, respectivamente. ${ }^{7}$ Este mismo concepto fue ratificado por Penner y cols. quienes mostraron que la adición de tobramicina y vancomicina juntas en polimetacrilato en lugar de utilizar cualquiera de los dos por separado, incrementó la elución de ambos antibióticos. ${ }^{8}$

Se demostró que la recomendación de utilizar 3,6 g de tobramicina y $1 \mathrm{~g}$ de vancomicina, cada $40 \mathrm{~g}$ de polimetacrilato es segura en cuanto a la toxicidad renal, pues la dosis no se administra, de manera completa, porque solo se utiliza una pequeña porción del cemento al recubrir la placa. ${ }^{8,9}$

El cemento óseo a base de polimetacrilato puede absorber agua hasta un $2 \%$ de su peso. Esta absorción e intercambio de fluidos permiten que algunas de las moléculas del fármaco sean liberadas de la matriz de polimetacrilato, principalmente aquellas cercanas a la superficie del cemento. ${ }^{10-12}$

Si bien hay múltiples estudios que respaldan el uso de clavos cubiertos de cemento con antibiótico para tratar la osteomielitis en la diáfisis de huesos largos, ${ }^{13-16}$ el uso de placas revestidas de cemento con antibiótico para la osteomielitis es todavía un tema controvertido, y se han publicado pocos casos. ${ }^{17,18}$

\section{CONCLUSIÓN}

Las placas revestidas de cemento con antibióticos representan una opción para el tratamiento de la falla de la osteosíntesis asociada a osteomielitis, como alternativa al enclavado endomedular en regiones donde estos no proveen una adecuada estabilidad mecánica.

Conflicto de intereses: Los autores no declaran conflictos de intereses.

ORCID de S. Argüelles: https://orcid.org/0000-0002-9002-5687

ORCID de M. P. Rodríguez: https://orcid.org/0000-0002-2616-0251

ORCID de E. Pereira: https://orcid.org/0000-0001-7307-7824

\section{BIBLIOGRAFÍA}

1. Krüger-Franke M, Carl C, Haus J. [Treatment of infected intramedullary osteosynthesis. A comparison of various therapeutic procedures]. Aktuelle Traumatol 1993;23(2):72-6. [En alemán] PMID: 8098574

2. Evans RP, Nelson CL. Gentamicin-impregnated polymethylmethacrylate beads compared with systemic antibiotic therapy in the treatment of chronic osteomyelitis. Clin Orthop Relat Res 1993;(295):37-42. PMID: 8403668

3. Pelissier Ph, Masquelet AC, Bareille R, Mathoulin Pelissier S, Amedee J. Induced membranes secrete growth factors including vascular and osteoinductive factors and could stimulate bone regeneration. J Orthop Res 2004;22(1):73-9. https://doi.org/10.1016/S0736-0266(03)00165-7

4. Rutledge B, Huyette D, Day D, Anglen J. Treatment of osteomyelitis with local antibiotics delivered via bioabsorbable polymer. Clin Orthop Relat Res 2003;(411(:280-7. https://doi.org/10.1097/01.blo.0000065836.93465.ed

5. Zalavras CG, Patzakis MJ, Holtom P. Local antibiotic therapy in the treatment of open fractures and osteomyelitis. Clin Orthop Relat Res 2004;(427):86-93. https://doi.org/10.1097/01.blo.0000143571.18892.8d

6. Mader JT, Stevens CM, Stevens JH, Ruble R, Lathrop JT, Calhoun JH. Treatment of experimental osteomyelitis with a fibrin sealant antibiotic implant. Clin Orthop Relat Res 2002;(403):58-72.

https://doi.org/10.1097/00003086-200210000-00011 
7. Adams K, Couch L, Cierny G, Calhoun J, Mader JT. In vitro and in vivo evaluation of antibiotic diffusion from antibiotic impregnated polymethylmethacrylate beads. Clin Orthop 1992;(278):244-52. PMID: 1563160

8. Penner MJ, Masri BA, Duncan CP. Elution characteristics of vancomycin and tobramycin combined in acrylic bonecement. J Arthroplasty 1996;11(8):939-44. https://doi.org/10.1016/s0883-5403(96)80135-5

9. Patzakis MJ, Zalavras CG. Chronic posttraumatic osteomyelitis and infected nonunion of the tibia: current management concepts. J Am Acad Orthop Surg 2005;13(6):417-27. https://doi.org/10.5435/00124635-200510000-00006

10. Bistolfi A, Massazza G, Verne E, Massè A, Deledda D, Ferraris S, et al. Antibiotic-loaded cement in orthopedic surgery: a review. ISRN Orthop 2011;2011:290851. https://doi.org/10.5402/2011/290851 10.5402/2011/290851

11. Kusy RP, Whitley JQ, Kalachandra S. Mechanical properties and interrelationships of poly(Methyl Methacrylate) following hydration over saturated salts. Polymer 2001;42(6):2585-95. https://doi.org/10.1016/S0032-3861(00)00613-3

12. Ayre WN, Denyer SP, Evans SL. Ageing and moisture uptake in polymethyl methacrylate (PMMA) bone cements. J Mech Behav Biomed Mater 2014;32(100):76-88. https://doi.org/10.1016/j.jmbbm.2013.12.010

13. Ohtsuka H, Yokoyama K, Higashi K, Tsutsumi A, Fukushima N, Noumi T, et al. Use of antibiotic-impregnated bone cement nail to treat septic nonunion after open tibial fracture. J Trauma 2002;52(2):364-6. https://doi.org/10.1097/00005373-200202000-00025

14. Norden CW. Experimental osteomyelitis. I. A description of the model. J Infect Dis 1970;122(5):410-8. https://doi.org/10.1093/infdis/122.5.410

15. Madanagopal SG, Seligson D, Roberts CS. The antibiotic cement nail for infection after tibial nailing. Orthopedics 2004;27(7):709-12. PMID: 15315038

16. Thonse R, Conway J. Antibiotic cement-coated interlocking nail for the treatment of infected nonunions and segmental bone defects. J Orthop Trauma 2007;21(4): 258-68. https://doi.org/10.1097/BOT.0b013e31803ea9e6

17. Liporace FA, Yoon RS. Use of an "antibiotic plate" for infected periprosthetic fracture in total hip arthroplasty. $J$ Orthop Trauma 2012;26(3):e18-e23. https://doi.org/10.1097/BOT.0b013e318216dd60

18. Conway JD, Hlad LM, Bark SE. Antibiotic cement-coated plates for management of infected fractures. Am J Orthop (Belle Mead NJ) 2015;44 (2):E49-E53. PMID: 25658083 